\title{
Ação do dimetil-sulfóxido na isquemia de retalhos randômicos de pele em ratos $^{1}$
}

\author{
The role of subcutaneous methyl-sulfoxide in a morphological study of random skin flaps \\ in rats
}

\author{
Kleder Gomes de Almeida², Djalma José Fagundes 3 , Mônica Cecília Bochetti Manna ${ }^{4}$ Edna Frasson de Souza \\ Montero ${ }^{5}$ \\ 1. Resumo da Tese de Mestrado do Programa de Pós-Graduação em Técnica Operatória e Cirurgia Experimental de Universidade Federal de \\ São Paulo - Escola Paulista de Medicina (UNIFESP-EPM). \\ 2. Mestre pelo Programa de Pós-Graduação em Técnica Operatória e Cirurgia Experimental, UNIFESP-EPM. \\ 3. Professor Adjunto do Depto. de Cirurgia e Coordenador do Programa de Pós-Graduação em Cirurgia e Experimentação, UNIFESP-EPM. \\ 4. Aluna nível de Doutorado do Programa de Pós-Graduação em Cirurgia e Experimentação, UNIFESP-EPM. \\ 5. Professora Afiliada do Departamento de Cirurgia, UNIFESP-EPM.
}

\begin{abstract}
RESUMO
Objetivo: Avaliar a ação do dimetil-sulfóxido (DMSO) na necrose distal de retalhos randômicos isquêmicos em ratos. Métodos: Foram utilizados 30 ratos machos, linhagem Wistar, peso entre 220 e $363 \mathrm{~g}$ e idade média de 3 meses. O retalho cutâneo dorsal $(8 \times 2 \mathrm{~cm})$ com pedículo cranial foi descolado, reposto em seu leito e suturado com poliamida 4.0. O grupo controle-CT (n=10) não recebeu nenhuma medicação, o grupo simulado-SM $(\mathrm{n}=10)$ recebeu o volume de $1 \mathrm{~mL}$ de solução salina subcutânea, dividida em dez aplicações ao longo do retalho, o grupo experimento-EX $(\mathrm{n}=10)$ recebeu a injeção de $1 \mathrm{ml}$ de DMSO 5\%. Após sete dias foram avaliadas as áreas de necrose distal e colhido material para o estudo histológico. Resultados: As medidas das áreas de necrose $(\mathrm{CT}=47,99, \mathrm{SM}=58,78, \mathrm{EX}=41,57)$ e as porcentagens das áreas de necrose $(\mathrm{CT}=29,98, \mathrm{SM}=36,73, \mathrm{EX}=23,99)$ mostraramse menores no grupo Ex $(\mathrm{p}<0,05)$. O estudo histológico qualitativo mostrou, no grupo Ex, maior presença de neovascularização, menor desestruturação dos anexos e do estroma conjuntivo e presença de fibroblastos em período mais precoce que nos dois outros grupos. Conclusão: O DMSO teve ação benéfica sobre os retalhos cutâneos randômicos em ratos, expressos pela menor área de necrose distal e pelo aspecto histológico de reparação tecidual mais precoce.
\end{abstract}

Descritores: Retalhos cirúrgicos. Isquemia. Pele. Ratos.

\section{ABSTRACT}

Purpose: To evaluate through the morphologic study (macro and microscopic) the effectiveness of DMSO in the genesis of the distal necrosis of random skin flaps in rats. Methods: 30 male rats were used, lineage Wistar, weight between 220 and $363 \mathrm{~g}$ and 3 months medium age. The skin flap $(8 \times 2 \mathrm{~cm})$ with remained cranial vessels it was unstuck, restored at his bed and sutured with polyamide 4.0. The control-group CT $(n=10)$ don't received any medication, the simulated group -SM $(n=10)$ it received the volume of $1 \mathrm{~mL}$ of subcutaneous saline solution, divided in ten applications along the skin flap, the experiment group ( $\mathrm{n}=10)$ it received the injection of $1 \mathrm{ml}$ of DMSO5\%. After seven days they were appraised the areas of distal necrosis and picked material for the histology study. Results: The measures of the necrosis areas (CT=47.99, SM=58.78, EX=41.57) and the percentages of the necrosis areas $(\mathrm{CT}=29.98, \mathrm{SM}=36.73, \mathrm{EX}=23.99)$ they were shown smaller in the EX group $(\mathrm{p}<0,05)$. The qualitative histology study showed, in the group EX, larger angiogenic presence, smaller destruction of the enclosures and of the conjunctive stroma and presence of fibroblasts in more precocious period than in the two other groups. Conclusion: The analysis of the collected data can infer that DMSO had beneficial action on the random skin flaps, expressed by the smallest area of distal necrosis and for the histology aspect of repairing tissue more precocious.

Key words: Surgical Flaps. Ischemia. Skin. Rats. 


\section{Introdução}

O reparo de lesões do sistema tegumentar com perda de substâncias após traumatismo, ressecção tumoral, infecção ou isquemia tecidual envolve o uso de retalhos cutâneos.

Para a confecção dos chamados retalhos randomizados a relação entre a área do retalho pretendido e a extensão do pedículo vascular, que irá manter a irrigação arterial e drenagem venosa, continua sendo um desafio para os cirurgiões. A isquemia a que fica submetido o retalho, principalmente nas primeiras horas de sua aplicação, é fundamental para determinar a extensão de sua viabilidade ${ }^{1-3}$.

Estudos experimentais em ratos demonstraram que o tempo para a formação do pedículo secundário ocorre em torno de nove dias ${ }^{1}$. A formação de hematoma ${ }^{2}$, edema ${ }^{3}$ e própria relação pedículo versus área do pedículo podem acarretar necrose da porção distal do retalho ao pedículo em porcentagens que variam de $9 \%$ a $65 \%$, de acordo com o modelo experimental testado ${ }^{1-8}$.

Considerando que o retalho randômico está exposto, logo após sua confecção, aos fenômenos de isquemia que levarão ao aparecimento de espécies reativas de oxigênio, uma droga que tenha ação de remover esses radicais poderá ser de extrema valia nessa fase. A droga deve estar disponível no sítio operatório em níveis farmacológicos e tempo adequados para exercer a ação desejada. Outra característica desejável é que ela possa ser aplicada em dose única.

Uma revisão da literatura das últimas duas décadas em trabalhos publicados nas áreas de farmacologia básica, uso terapêutico e toxicidade demonstrou a propriedade de varredor de radicais livres do dimetil-sulfóxido (DMSO) quando aplicado antes, durante ou algumas horas após a lesão tecidual ${ }^{12}$.

O uso do DMSO no fenômeno do estresse oxidativo mostrou efeitos benéficos, aumentando a viabilidade dos retalhos cutâneos em diferentes modelos experimentais, em diferentes concentrações e vias de administração $0^{4-6,9-18}$.

Uma droga como o DMSO pareceu ser uma escolha factível considerando suas características de agente

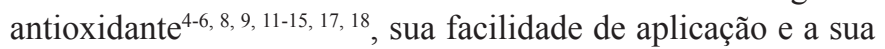
solubilidade em líquidos orgânicos, permitindo a sua adequada concentração em níveis farmacológicos 9, 17, 19 .

Para obter, de modo rápido e seguro, nível adequado de concentração da droga no local desejado tem-se a opção da via subcutânea, o que possibilita também que a aplicação seja realizada em dose única durante ou logo após o ato operatório.

A proposta do estudo foi verificar a eficácia do DMSO na prevenção de necrose distal, em um modelo de retalho randomizado em ratos, usando a via de administração subcutânea da droga.

\section{Métodos}

O estudo foi submetido à apreciação e aprovação da Comissão de Ética em Pesquisa do Hospital São Paulo Universidade Federal de São Paulo - Escola Paulista de Medicina .

\section{Amostra}

Trinta ratos machos (Rattus norvegicus albinus) da linhagem Wistar, pesando entre 220 e $363 \mathrm{~g}$, com idade média de três meses, foram distribuídos aleatoriamente em três grupos:

- Grupo CT (controle) - Um retalho cutâneo dorsal de base cranial foi confeccionado, elevado e recolocado no seu leito.

- Grupo SM (simulado) - Um retalho cutâneo dorsal de base cranial foi confeccionado, elevado, recolocado no seu leito e recebeu a injeção subcutânea do excipiente (solução salina de cloreto de sódio $0,9 \%$ ).

- Grupo EX (experimento) - Um retalho cutâneo dorsal de base cranial foi confeccionado, elevado, recolocado no seu leito e recebeu a injeção subcutânea de dimetil-sulfóxido (DMSO) a $5 \%$.

\section{Procedimento operatório}

Os animais foram anestesiados com tiopental sódico, na dose de $50 \mathrm{mg} / \mathrm{kg}$, intraperitoneal, e posicionados em decúbito ventral, com imobilização dos membros com fita adesiva. Após foi realizada a retirada de pêlos do dorso e demarcação de uma área de aproximadamente $16 \mathrm{~cm}^{2}$, com $2 \mathrm{~cm}$ de base cranial e $8 \mathrm{~cm}$ de comprimento em direção caudal.

Nos animais do grupo CT, o retalho cutâneo de base cranial pré-estabelecido foi confeccionado pela incisão com bisturi de lâmina quinze na área demarcada com azul de metileno. O retalho cutâneo foi dissecado e descolado do plano músculo-aponevrótico adjacente, elevado do leito, recolocado e suturado ao mesmo, com sutura contínua interrompida a cada $2 \mathrm{~cm}$ com fio monofilamentar de poliamida 4.0.

Nos animais do grupo SM demarcou-se também com azul de metileno, os dois terços distais do retalho por centímetro quadrado $\left(10 \mathrm{~cm}^{2}\right)$ e repetiram-se os procedimentos operatórios do grupo CT. Após a sutura, no centro de cada área demarcada de $1 \mathrm{~cm}^{2}$, foi injetado $0,01 \mathrm{~mL}$ do excipiente (solução salina de cloreto de sódio $0,9 \%$ ), com seringa descartável de insulina e agulha $13 \times 3,8$.

Nos animais do grupo EX repetiu-se os procedimentos operatórios e de demarcação do grupo SM. Após a sutura, em cada área demarcada foi injetado $0,01 \mathrm{~mL}$ de DMSO 5\%, com seringas descartáveis de insulina e agulha 13x3,8.

Os animais permaneceram em observação até recuperação anestésica, avaliada pelo retorno dos reflexos abolidos e pela movimentação ativa e/ou estimulada na gaiola. 


\section{Observação pós-operatória}

Durante sete dias os animais foram observados quanto à movimentação ativa e/ou estimulada na gaiola, pelos sinais de brilho do olho e/ou presença de secreção nasal, que são sinais indiretos de sofrimento (dor ou infecção), sendo o acesso à água e alimentação livres. Não houve necessidade de realização de curativos devido ao aspecto da ferida operatória, assim como pela localização da mesma.

\section{Coleta de dados}

No $7^{\circ}$ dia de pós-operatório os animais foram anestesiados pela mesma técnica utilizada para os procedimentos operatórios, pesados e fotografados com equipamento profissional (Pentax ${ }^{\circledR} \mathrm{K}-100$, lente $28-80 \mathrm{~mm}$, abertura oito, distância focal $30 \mathrm{~cm}$; filme $\operatorname{Kodak}^{\circledR} 35 \mathrm{~mm}$, ASA100), sendo que essas fotografias foram posteriormente digitalizadas (resolução de 640 pontos na horizontal e 480 pontos na vertical, 24 bits de cores), com demarcação da área de necrose e cálculo das áreas e respectivas medianas (ImageLab® 2000).

Retirou-se uma faixa de tecido de $8 \times 0,5 \mathrm{~cm}$ de toda extensão da periferia do retalho, dividindo-a em 3 áreas distintas de $0,5 \times 0,5 \mathrm{~cm}$.

Determinou-se como:

- Área A: proximal, contendo tecido sadio;

- Área B: intermediária, com tecido de transição (sadio e necrose) e situada entre as áreas proximal e distal;

- Área C: distal e contendo área de necrose.
As peças foram imersas em frascos individuais com formol tamponado a $10 \%$, fechados hermeticamente e enviadas para processamento histológico e coloração pela hematoxilinaeosina, para o estudo histológico qualitativo das alterações.

Os dados foram submetidos a testes de análise de variância por postos de Kruskal-Wallis $(p<0,05)$.

\section{Resultados}

A análise de variância percentual $(\Delta \%)$ dos pesos (em gramas) inicial e final dos animais não mostrou diferença significante $(p<0.05)$ entre os grupos: Controle (média $=261,0)$, grupo simulado (média $=306,1$ ) e grupo experimento (média $=303,5)$. Associado às avaliações diárias dos animais, os dados revelaram que não houve comprometimento da higidez dos animais em nenhum dos grupos, em particular do grupo experimento, mostrando que a droga não teve efeitos deletérios.

A análise de variância por postos permitiu verificar que os animais submetidos à injeção de DMSO apresentaram uma menor área $(\mathrm{CT}=47,99, \mathrm{SM}=58,78, \mathrm{EX}=41,57) \mathrm{e}$ porcentagem de necrose distal do retalho $(\mathrm{CT}=29,98$, $\mathrm{SM}=36,73, \mathrm{EX}=23,99)$ em comparação como grupo controle e simulado (Figuras 1, 2 e 3).

O estudo histológico mostrou no grupo que recebeu DMSO maior presença de neovascularização, menor desestruturação dos anexos e do estroma conjuntivo e presença de fibroblastos em período mais precoce que grupos que não receberam a droga (Figura 4).

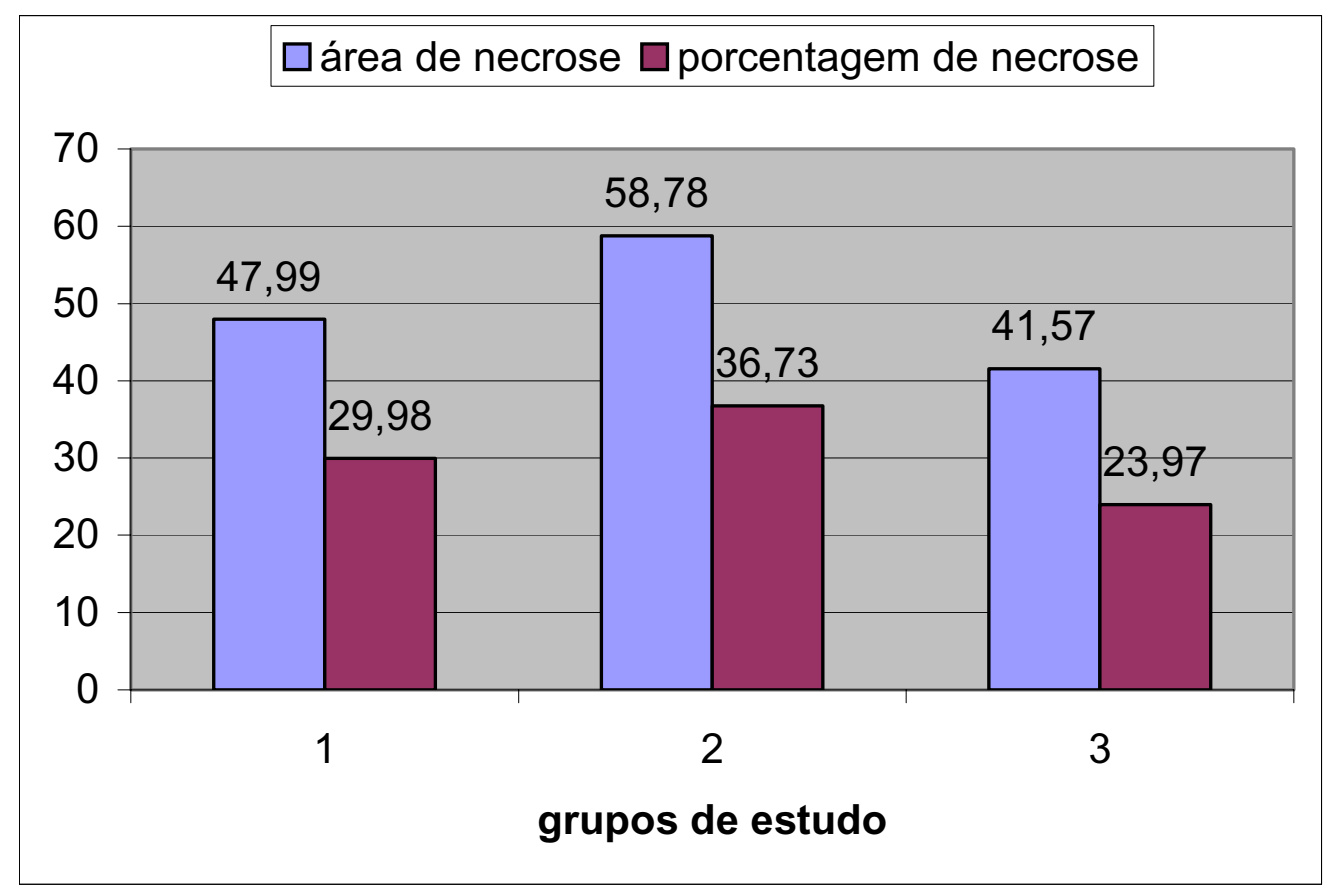

FIGURA 1 - Médias das áreas de necrose distal nos retalhos cutâneos de ratos e médias das porcentagens das áreas de necrose distal nos retalhos cutâneos de ratos nos grupos controle (1), simulado (2) e experimento (3), aos sete dias de observação 


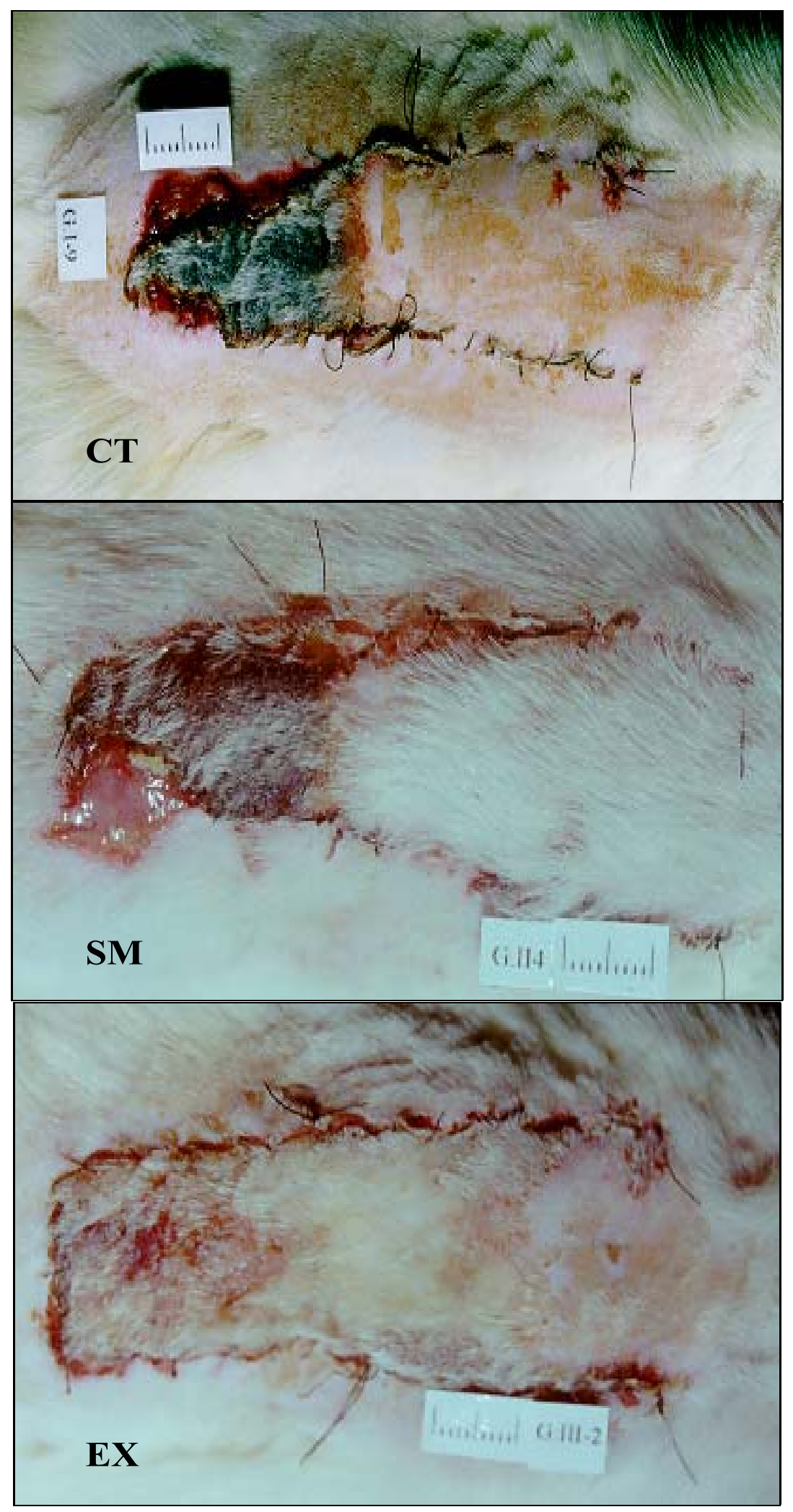

FIGURA 2 - Seqüência de fotografias mostrando a área de necrose em animal dos grupos CT, SM e EX, aos sete dias de observação. Nota-se que no grupo EX a área de necrose é menor e de menor intensidade que nos grupos CT e SM 

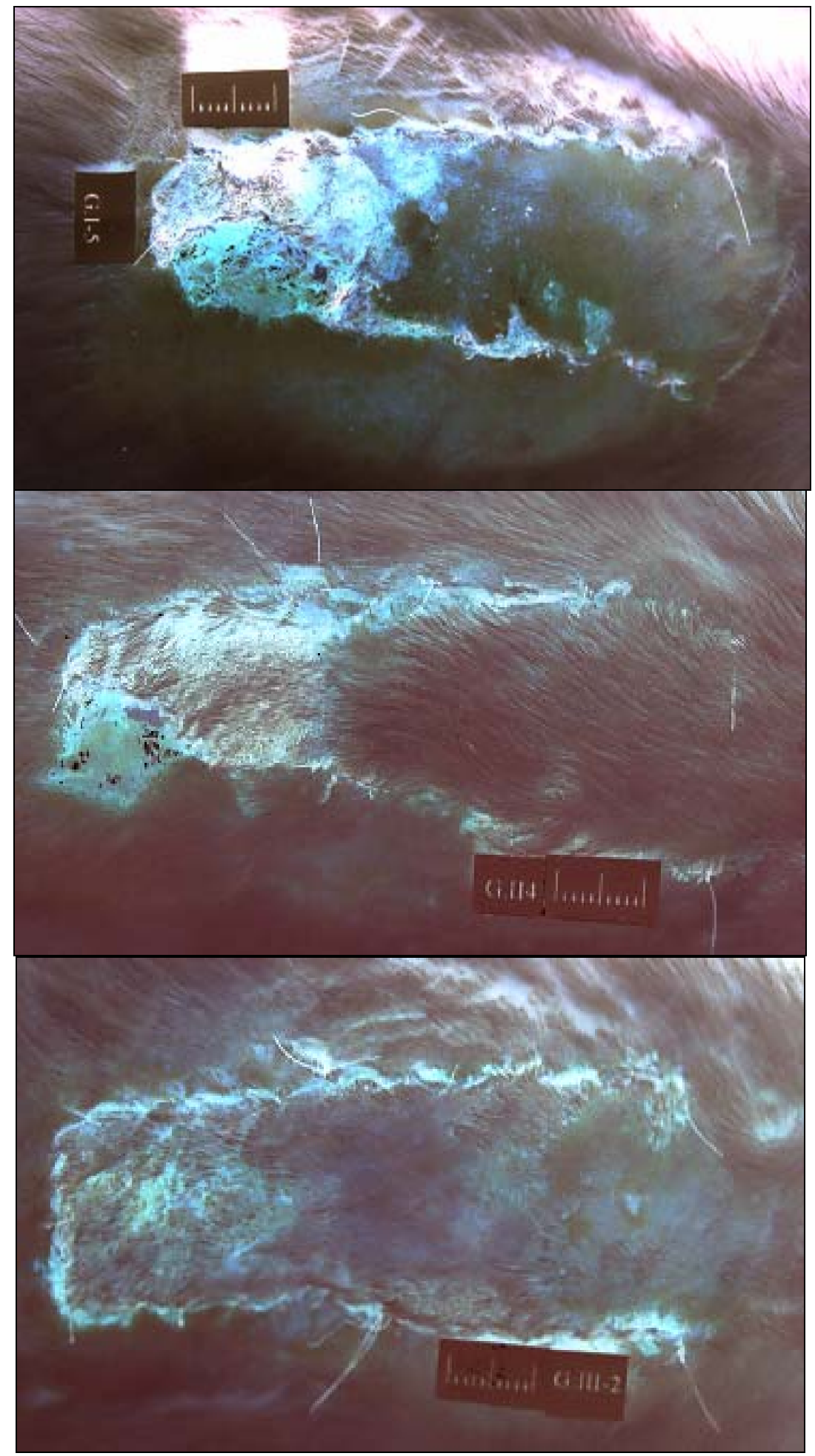

FIGURA 3 - Seqüência de fotografias com o artifício de subtração de cores para tornar mais evidente a área de necrose (área clara) em animal dos grupos CT, SM e EX, aos sete dias de observação. Nota-se que no Grupo EX a área esbranquiçada é menor e de menor intensidade que nos grupos CT e EX 

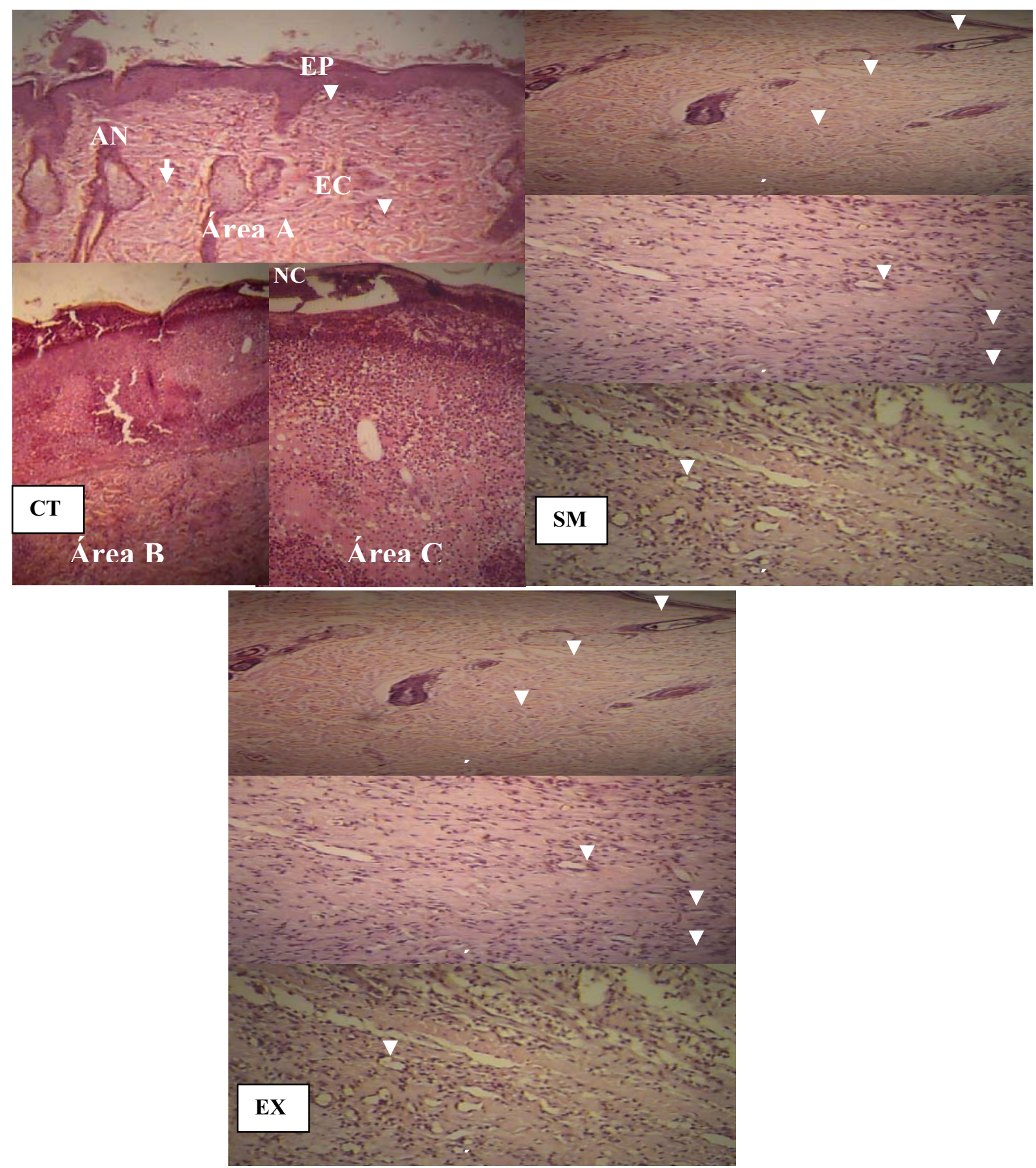

FIGURA 4 - Seqüência de fotomicrografias dos grupos CT, SM e EX mostrando: epitélio preservado (EP), anexos (AN) preservados e estroma conjuntivo (EC), vasos (VS), estroma conjuntivo com proliferação de fibroblastos (FB), infiltrado inflamatório com neutrófilos (NT), necrose epitelial (NC), infiltrado de polimorfonucleares (PL) e neovascularização (NV) 


\section{Discussão}

A relação entre a largura do pedículo e o comprimento do retalho é fundamental no estabelecimento da sua viabilidade. $\mathrm{A}$ isquemia e conseqüente necrose estão na dependência do aporte sangüíneo permitido pelos vasos do pedículo ${ }^{20,21}$. Somente a partir do terceiro dia de pós-operatório começam a ser identificados sinais de neovascularização no retalho desde o leito e da área cutânea vizinha, sendo que o pedículo secundário estará completo ao redor do nono dia ${ }^{1}$.

Considerando que o processo de estresse oxidativo tem início precoce, já aos cinco minutos de pós-operatório, e que a capacidade antioxidante pode estar prejudicada pela dificuldade em atingir níveis locais eficazes, surgiu a proposta de pesquisarse uma droga antioxidante direta e para uso precoce no sitio operatório.

Para causar menor trauma no local da injeção atentouse para o volume e o tipo de agulha, não piorando a isquemia por compressão local ${ }^{3,4}$.

A via de administração subcutânea foi a que se mostrou mais viável no projeto piloto para a dispersão do volume injetado, em detrimento da via intradérmica.

As outras vias de administração enteral (via oral ou retal) e parenteral (intravenosa, intra-arterial e intraperitoneal) foram descartadas porque a intenção era atingir concentração da droga no sítio operatório sem a interferência da distribuição sistêmica. O uso tópico não foi considerado pela necessidade de aplicações diárias e dificuldade em dispersar a droga de modo uniforme na ferida operatória.

Dentre as substâncias que removem as espécies reativas de oxigênio o dimetil-sulfóxido (DMSO) mostrou-se promissor pela sua reconhecida capacidade antioxidante em estudos de retalhos cutâneos isquêmicos ${ }^{4-6,8-11,13-18}$ e por possibilitar uma concentração farmacologicamente ativa em um volume compatível com o preestabelecido ${ }^{9,11,16,19}$.

A concentração da droga pode variar de acordo com a via de administração. A administração por via enteral (oral, retal) $)^{6,23}$, ou parenteral (intravenosa, intraperitoneal, intra-arterial) ${ }^{9,10,11,22,24}$ é em torno de 1,5 a $2 \mathrm{mg} / \mathrm{kg}$ de peso $^{6,9,10,16,24}$. O uso tópico usa concentrações que variam de 5 a $60 \%$, 12, 13, 14, 15 . $\mathrm{O}$ uso intradérmico utiliza concentrações desde $0,5,1,5 \%{ }^{24} \mathrm{a}$ $12 \%{ }^{12}$. A via transcutânea, em que o DMSO é usado como veículo de vacinas, a concentração varia de 1 a $5 \%{ }^{19}$.

No delineamento da pesquisa optou-se então pela concentração de 5\% de DMSO e por um volume total de injeção de $1 \mathrm{~mL}$, obtendo-se assim uma dose total de $5 \mathrm{mg}$, dose esta próxima a recomendada pela literatura para o uso intradérmico e transcutâneo.

Referências específicas sobre a aplicação da droga por via subcutânea não foram encontradas na revisão da literatura .

Considerou-se no que o rato seria o animal ideal para as condições de trabalho em nosso meio e também para estudos de retalhos cutâneos isquêmicos ${ }^{4-6,9-11,13-18}$, em detrimento do coelho $^{8,14}$, como modelo animal experimental.

Para a confecção dos retalhos isquêmicos são referidos na literatura modelos variáveis de proporção entre os tamanhos do retalho e do pedículo. A proporção varia: 2,5:1 a 5:1. Os retalhos têm dimensão, em centímetros, de $7 \times 2^{3}, 10 \times 4^{6}, 2 \times 8^{7}$, $10 \times 2,5^{8}, 9 \times 4^{10}, 10 \times 2,5^{14}$.

Optou-se pela realização de um retalho de $8 \times 2 \mathrm{~cm}$ com proporção de 4:1 por ser um tamanho intermediário entre os de uso corrente na literatura . Também no projeto piloto o modelo apresentou características da área de necrose que possibilitavam o estudo adequado do antioxidante.

O período de observação dos retalhos foi estabelecido até o sétimo dia de pós-operatório, uma vez que nesta data já está bem definida a eventual área de necrose, além do processo de angiogênese e formação de neovascularização a partir do leito e da área perimetral do retalho já estarem instalados ${ }^{1,23,24}$.

$\mathrm{O}$ acompanhamento diário dos animais não evidenciou nenhum comprometimento da ferida operatória. A evolução ponderal foi considerada como um índice de avaliação do estado de higidez dos animais . A análise de variância mostrou que a diferença percentual do peso nos três grupos não foi estatisticamente significativa. $\mathrm{O}$ achado mostrou que, de modo indireto, tanto os atos operatórios quanto a droga, não afetaram de modo importante a higidez dos animais.

A extensão da área de necrose foi estabelecida como parâmetro de avaliação da eficácia da droga (Figura 1). Para determinação da área de necrose foi escolhido o método de fotografar as feridas operatórias com equipamento fotográfico profissional com um tripé, que manteve sempre uma mesma distância focal entre a lente e o objeto da fotografia. O mesmo técnico fotografou todas as feridas usando um tipo padronizado de filme fotográfico e sensibilidade. As fotos obtidas foram reveladas e digitalizadas em um programa de computação (ImageLabß) que permitiu a subtração de cores para mensuração da área de necrose e o cálculo da porcentagem destas áreas (Figura 2).

A análise de variância por postos destes resultados permitiu verificar que os animais submetidos à injeção de DMSO apresentaram uma menor área e porcentagem de necrose distal do retalho em comparação com os grupos controle e simulado (Gráfico 1).

O grupo simulado, no entanto, apresentou uma área de necrose mais extensa em relação ao grupo controle. Foi aventada a hipótese de que a injeção de solução salina possa ter funcionado como uma barreira para a vascularização, agindo da mesma forma que um edema, embora o volume da injeção tenha sido escolhido de modo a minimizar este efeito de barreira. O edema e a formação de hematoma, ou seja, barreiras físicas mostraram ser prejudiciais à vitalidade de retalhos cutâneos randômicos ${ }^{2,3}$. Um estudo com maior número de animais deve ser realizado para verificar se a diferença é apenas casual ou se a barreira física da solução salina é de fato o fator causal da diferença encontrada.

O grupo experimento, apesar de ter recebido um volume de líquido semelhante ao grupo simulado, apresentou uma extensão de necrose distal menor, provavelmente pela ação farmacológica do DMSO.

A via subcutânea, na concentração de droga usada, mostrou eficácia semelhante às outras vias de administração e dosagens $^{4-6,8-11,13-15,17,18}$. 
Considerando que os fenômenos do estresse oxidativo já são observados aos cinco minutos de pós-operatório e permanecem estáveis até a terceira hora ${ }^{4,5,7}$, a vantagem da aplicação subcutânea está no conhecimento teórico de se colocar a droga o mais próximo possível do local em que sua ação se faz necessária, ou seja, no sítio operatório.

Outra vantagem é a dose bem menor da droga do que a usada na via enteral ou parenteral. A droga não precisa ser administrada previamente ou repetidamente no período pósoperatório para atingir os níveis séricos de concentração farmacológica desejada ${ }^{6,7,8}$

Em relação à via tópica, as vantagens da via subcutânea são a aplicação única, não sendo necessárias aplicações diárias, e a dificuldade de dispersão da droga sobre uma ferida operatória.

Uma vez que os resultados mostraram uma ação do DMSO por via subcutânea os pressupostos teóricos de suas vantagens foram alcançados. O avanço do conhecimento estará no melhor entendimento de uma relação de concentração/volume da droga injetada.

A avaliação da ação antioxidante também foi avaliada pelo estudo morfológico qualitativo das células comumente presentes em um processo de reparação ou cicatrização tecidual. Foram colhidas amostras de pele na área proximal do retalho, onde a necrose foi inexistente, na área intermediária, entre o pedículo e a porção distal do retalho, onde áreas vitalizadas e necrose parcial foram identificadas, e na área distal do retalho onde a necrose eram evidente.

Os achados histológicos foram semelhantes nas áreas proximal e intermediária dos grupos controle e simulado. A área proximal mostrou epitélio íntegro com anexos conservados, estroma conjuntivo com mínimo ou ausente infiltrado inflamatório. A área intermediária mostrou um estroma desestruturado pelo infiltrado inflamatório de polimorfonucleares e focos de tecido necrótico. $\mathrm{Na}$ área intermediária do grupo experimento, além de um infiltrado inflamatório de polimorfonucleares menos denso, foi possível identificar uma discreta proliferação de fibroblastos, evidenciando um processo cicatricial mais avançado que nos dois outros grupos (Figura 3).

$\mathrm{Na}$ área distal do retalho no grupo controle e simulado os achados foram semelhantes, com áreas de necrose tecidual, infiltrado inflamatório denso, desestruturação dos anexos da pele e alguns vasos neoformados. No grupo experimento os achados foram semelhantes, porém com menor quantidade de neutrófilos e maior freqüência de vasos neoformados.

A análise histológica qualitativa permite inferir que a droga pode ter sido responsável pela maior presença de fibroblastos na área intermediária e pela maior freqüência de vasos neoformados na área distal, o que revela um processo de reparação tecidual mais adequado.

Os achados histológicos devem ser aprimorados com estudo quantitativo morfométrico dos diferentes elementos celulares, inclusive com coloração específica para fibroblastos e fibras colágenas.

A literatura recente mostra que a pesquisa da identificação da apoptose ${ }^{25}$ e dos fatores ligados à remoção de ânions superóxidos serão fundamentais para o avanço do conhecimento das drogas, em especial do DMSO, como protagonistas importantes na manutenção da vitalidade de retalhos cutâneos randômicos.

A contribuição desta pesquisa foi estabelecer a via de administração subcutânea como uma opção vantajosa do DMSO, sobre as demais vias de administração, na confecção de retalhos randômicos em ratos e ratificar a ação favorável da droga na prevenção de necrose, agindo sobre as espécies reativas de oxigênio.

\section{Conclusão}

A avaliação morfológica de retalhos cutâneos randômicos em ratos mostrou que a administração subcutânea de dimetil-sulfóxido (DMSO), na concentração de $5 \%$, foi eficaz na redução da área de necrose distal.

\section{Referências}

1. Chem RC, Perin EC, Maracaja PF. Estudo da revascularização de retalhos em ratos. AMRIGS. 1982;26:22-6.

2. van der Sllot PG, Seikaly H, Harris JR. Effetcs of noncompressive hematoma on free flap viability. J Otolaryngol. 2002;31:144-6.

3. Acevedo-Bogado CE, Bins Eli J, D'Campora AJ, Neves RE. Efeito da hialuronidase na sobrevida de retalhos cutâneos em ratas. Acta Cir Bras. 2002;17:14-16.

4. Cymrot M. Comportamento do estresse oxidativo e da capacidade antioxidante total em ratos submetidos a retalhos cutâneos isquêmicos [Tese - Doutorado]. Universidade Federal de São Paulo - Escola Paulista de Medicina; 1999.

5. Okamoto RH. Estresse oxidativo local e sistêmico na fase aguda, em ratos submetidos a retalhos cutâneos isquêmicos [Tese Doutorado]. Universidade Federal de São Paulo - Escola Paulista de Medicina; 2001.

6. Duarte I, Ferreira LM. Efeito do dimetilsulfóxido sobre a necrose de retalhos cutâneos, em ratos. Rev Bras Cir. 1997;87:159-64.

7. Kryger Z, Zhang F, Dogan T, Cheng C, Lineaweaver WC, Buncke HJ. The effects of VRGF on survival of random flap in the rat: examination of various routes of administration. Br J Plast Surg. 2000;53:234-9.

8. Raposio E, Caregnato P, Renzi M, Maragara A, Ferrando G, Barabino P, Capello C, Gualdi A, Molinari R, Santi PL. Modèle experimental pour l'évaluation d'une solution topique améliorant la survie des lambeaux myocutanés. Ann Chir Plast Esthet. 2002; 47:21921.

9. Ali BH. Dimethyl sulfoxide: recent pharmacological and toxicological research. Vet Hum Toxicol. 2001;43:228-31.

10. Carpenter RJ, Angel MF, Moragan RF. Dimethyl sulfoxide increases the survival of primary ischemic island skin flaps. Otolaringol Head Neck Surg. 1994;110:228-31.

11. Werker PM, Kon M, Green CJ, Ambrose I, Hidalgo A. Oxidative processes and free radical scavengers in ischaemia-reperfusion injury in adipocutaneous flaps: in vitro lipid peroxidation assessment. Br J Plast Surg. 1995;48:590-6.

12. Sjögren F, Anderson C. The spectrum of inflammatory cell response to dimethyl sulfoxide. Contact Dermatitis. 2000;42:216-21.

13. Rand-Luby L, Pommier RF, Williams ST, Woltering EA, Small KA, Fletcher WS. Improve outcome of surgical flaps treated with topical dimethylsulfoxide. Ann Surg. 1996;224:583-9. 
14. Raposio E, Santi PL. Pharmacological enhancement of cutaneous flap survival with topical dimethylsulfoxide and hydrogen peroxide. Br J Plast Surg. 1998;51:551-4.

15. Kim N, Khalili M, Henary MM, Strekowski 1, Michniak BB. Percutaneous penetration enhancement activity of aromatic dimethylliminosulforanes. Int J Pharmacol. 1999;187:219-29.

16. Kirchner B, Reiher M. The secret of dimethyl sulfoxide-water mixtures. A quantum chemical study of 1DMSO-nwater cluster. J Am Chem Soc. 2002;124:6206-15.

17. Jacob S, Bischel M, Herscheler RJ. Dimethylsulfoxide: A new concept in pharmacotherapy. Curr Ther Res. 1964;6:134-5.

18. Kligman AM. Topical pharmacology and toxicology of dimethyl sulfoxide - Part 1. J Am Med Assoc. 1993;193:140-6.

19. Heckert RA, Elankumaran S, Oshop GL, Vakharia VN. A novel transcutaneous plasmid-dimethylsulfoxide delivery technique for avian nucleic acid immunization. Vet Immunol Immunopathol. 2002;89(1-2):67-81.
20. Wakata N, Sugimoto H, Iguchi H, Nomoto N, Kinoshita M. Bupivacaine hydrochloride induces muscle fiber necrosis and hydroxyl radical formation-dimethyl sulphoxide reduces hydroxyl radical formation. Neurochem Res. 2001;26(7):841-4.

21. Salim AS. Role of oxygen-derived free radical scavengers in the treatment of recurrent pain produced by chronic pancreatitis: a new approach. Arch Surg. 1991;126(9):1109-14

22. Nakamuta M, Ohta S, Tada S, Tsuruta S, Sugimoto R, Kotoh K, Kato M, Nakashima Y, Enjoji M, Nawata H. Dimethyl sulfoxide inhibits dimethylnitrosamine-induced hepatic fibrosis in rats. Int J Mol Med. 2001;8(5):553-60.

23. Ferreira, LM. Retalhos cutâneos. 1.ed. São Paulo: Atheneu; 2001. 24. Destro MWB. Retalhos cutâneos. 1.ed. São Paulo: Atheneu; 1996.

25. Herdener M, Heigold S, Saran M, Bauer G. Target cell-derived superoxide anions cause efficiency and selectivity of intercellular induction of apoptosis. Free Radic Biol Med. 2000;29(12):126071.

Conflito de interesse: nenhum

Fonte de financiamento: nenhuma

Correspondência:

Djalma José Fagundes

Rua Botucatu, 740

04023-900 São Paulo - SP

Recebimento: $19 / 07 / 2004$

Revisão: 28/08/2004

Aprovação: 30/09/2004

\section{Como citar este artigo:}

Almeida KG, Fagundes DJ, Manna MCB, Montero EFS. Ação do dimetil-sulfóxido na isquemia de retalhos randômicos de pele em ratos. Acta Cir Bras [serial online] 2004 Nov-Dez;19(6). Disponível em URL: http://www.scielo.br/acb [também em CDROM].

*Figuras coloridas disponíveis em www.scielo.br/acb 